\section{Energy Systems High Pressure Test Laboratory}

The purpose of the Energy Systems High Pressure Test Laboratory at NREL's Energy Systems Integration Facility (ESIF) is to provide space where high pressure hydrogen components can be safely tested. High pressure hydrogen storage is an integral part of energy storage technology for use in fuel cell and in other distributed energy scenarios designed to effectively utilize the variability inherent with renewable energy sources. The high pressure storage laboratory is co-located with energy storage activities such as ultracapacitors, super conducting magnetic flywheel and mechanical energy storage systems laboratories for an integrated approach to system development and demonstration.

Hazards associated with hydrogen storage at pressures up to 10,000 psi include oxygen displacement, combustion, explosion, and pressurization of room air due to fast release and physical hazards associated with burst failure modes. A critical understanding of component failure modes is essential in developing reliable, robust designs that will minimize failure risk beyond the end of service life. Development of test protocol for accelerated life testing to accurately scale to real world operating conditions is essential for developing regulations, codes and standards required for safe operation.

NREL works closely with industry partners in providing support of advanced hydrogen technologies. Innovative approaches to product design will accelerate commercialization into new markets. NREL works with all phases of the product design life cycle from early prototype development to final certification testing.

\section{Laboratory Specifications}

The walls of the Energy Systems High Pressure Test Laboratory are built from concrete, capable of sustaining an overpressure condition or in the case of a component failure during test, and can act as secondary containment. Remote data and remote cameras are used for test observation, providing the added safety mechanisms needed to safely perform high pressurized tests.

\section{Application Scenarios}

High pressure tests are performed on hydrogen components, primarily for the validation of developing new codes and standards for high pressure hydrogen applications. The following types of tests can be performed:

- Performance

- Component and system level efficiency

- Strength of materials and hydrogen compatibility

- Safety demonstration

- Model validation

- Life cycle reliability

\section{Partner with Us}

Work with NREL experts and take advantage of the state-of-the-art capabilities at the ESIF to make progress on your projects, which may range from fundamental research to applications engineering. Partners at the ESIF's Energy Systems High Pressure Test Laboratory may include:

- High pressure testing component manufacturers

- Codes and standards development organizations

- Certification laboratories

- Government agencies

- Universities

- Other National laboratories

\section{Contact Us}

If you are interested in working with NREL's

Energy Systems High Pressure Test Laboratory, please contact:

\section{ESIF Manager \\ Carolyn Elam \\ Carolyn.Elam@nrel.gov \\ 303-275-4311}

\section{Major Laboratory}

Equipment

- High pressure systems capable of cyclic loading and fast fill

- Hydrogen storage and recovery capability for extended life testing

- Automated operating systems with safety interlocks

- Pressure rated pumps, compressors and control system components

- Secondary containment vessels for end of life testing

- Hydraulic pressurization capability for proof testing

- Advanced data acquisition and monitoring equipment
National Renewable Energy Laboratory 15013 Denver West Parkway, Golden, CO 80401 303-275-3000 - www.nrel.gov
NREL is a national laboratory of the U.S. Department of Energy

Office of Energy Efficiency and Renewable Energy

Operated by the Alliance for Sustainable Energy, LLC

NREL/FS-5500-52855 • October 2011 